\title{
Novo marco legal sobre regularização fundiária: novos conceitos, velhos dilemas
}

\author{
Andreza Aparecida Franco Câmara ${ }^{1}$
}

\begin{abstract}
Resumo
O presente estudo abordará sobre a nova lei geral de regularização fundiária editado em 2017. Objetivo - Pretende-se analisar os principais aspectos do novo marco legal de regularização fundiária e examinar o instituto da legitimação fundiária e as principais teses de inconstitucionalidade apresentadas da Ação Direta de Inconstitucionalidade (ADI). Materiais e Métodos - Apresentando metodologia qualitativa, por meio do método hipotético-dedutivo será empregada a revisão de literatura, a análise de legislação e jurisprudência dos tribunais superiores. Resultados - Verificou-se que a legislação flexibilizou alguns procedimentos anteriormente previstos em outras normas, com o propósito de resolver situações fundiárias por meio da titulação dos ocupantes, criando institutos jurídicos que se confrontam a ordem constitucional vigente. Conclusões - Conclui-se que a Lei ${ }^{\circ}$. 13.465/2017, ao reestruturar os regimes de regularização fundiária urbana, com ênfase na distribuição de títulos de propriedade, embora estabeleça critérios de acesso da população de baixa renda, reforça a desigualdade social ao contribuir para a concentração de terras.
\end{abstract}

Palavras-chave: Regularização fundiária; Legitimação fundiária; ADI 5.771.

\section{Nouveau cadre juridique sur la régularisation des terres: nouveaux concepts, anciens dilemmes}

\section{Résumé}

Cette étude portera sur la nouvelle loi générale sur la régularisation foncière édictée en 2017. Objectif - Elle vise à analyser les principaux aspects du nouveau cadre juridique de régularisation foncière et à examiner l'institut de légitimation foncière et les principales thèses d'inconstitutionnalité présentées dans l'Action Directe de Inconstitutionnalité (DJA). Matériel et méthodes - Présentation de la méthodologie qualitative, utilisant la méthode hypothéticodéductive, une revue de la littérature, une analyse de la législation et de la jurisprudence des tribunaux supérieurs. Résultats - Il a été constaté que la législation assouplissait certaines procédures précédemment prévues dans d'autres règles, dans le but de résoudre les situations de régime foncier par l'attribution de titres aux occupants, créant des instituts juridiques qui confrontent l'ordre constitutionnel actuel. Conclusions - Il est conclu que la loi $\mathrm{n}^{\circ}$. 13.465 /

\footnotetext{
${ }^{1}$ Doutora em Ciências Jurídicas e Sociais pela Universidade Federal Fluminense (UFF). Professora Adjunta no Departamento de Direito de Macaé (MDI), do Instituto de Ciências da Sociedade de Macaé (ICM) da UFF. Líder do Grupo de Pesquisa do Diretório do CNPq Observatório de Estudos e Pesquisa do Interior: Território, Populações Tradicionais e Políticas Públicas/UFF. Pesquisadora FAPERJ.
} 
2017, en restructurant les régimes de régularisation foncière urbaine, en mettant l'accent sur la répartition des titres de propriété, bien qu'elle établisse des critères d'accès pour la population à faible revenu, elle renforce les inégalités sociales en contribuant à la concentration des terres.

Mots-clés: Régularisation foncière; Régime foncier; ADI 5.771.

\section{INTRODUÇÃO}

O processo de urbanização nas cidades brasileiras, em grande parte, apresenta como características a fragmentação urbana e a exclusão social. Ocorre o acúmulo dos espaços de desigualdades, além da falta de infraestrutura e justiça.

Diversos fatores endógenos e exógenos são apontados para configurar esse modelo concentrador nos espaços periféricos, que acarretam, por consequências, desigualdades sociais locais e regionais, além da falta de infraestrutura e políticas públicas que engendram essa lógica de gentrificação. Tomando esses fatores como base empírica, iniciativas federais são implantadas para viabilizar um desenvolvimento inclusivo das cidades considerando o conjunto de seus habitantes.

Dentre essas medidas encontra-se a edição da Lei $n^{\circ} .13 .465 / 2017$, que cria a obrigação dos entes públicos em implementarem políticas públicas visando o cumprimento da função social da propriedade e o incremento do direito humano fundamental à moradia, por meio do desenvolvimento urbano, da sustentabilidade econômica, social e ambiental, e criando um conjunto de instrumentos que desburocratizam e dão celeridade aos procedimentos de aprovação e do registro da Certidão da Regularização Fundiária (CRF).

A nova legislação acentuou a concessão da titulação jurídica aos ocupantes dos núcleos informais, dada a ampliação de legitimados para requerer a regularização e o acréscimo de instrumentos de titulação. No presente estudo, objetivou-se discutir os aspectos gerais do novo marco legal de regularização fundiária, apresentando principais elementos conceituais e examinando o instituto da legitimação fundiária e as principais teses de inconstitucionalidade apresentadas da Ação Direta de Inconstitucionalidade (ADI) 5.771/DF.

\section{MATERIAIS E MÉTODOS}

A metodologia empregada foi a qualitativa, por meio de pesquisa bibliográfica e documental, com análise da legislação de regularização fundiária em vigor e do processo judicial que tramita no Supremo Tribunal Federal visando a declaração de inconstitucionalidade formal e material da Lei $\mathrm{n}^{\mathrm{o}}$. 13.465/2017. 


\section{DISCUSSÕES E RESULTADOS}

Com o advento da Lei $\mathrm{n}^{\mathrm{o}}$. 13.465, de 11 de julho de 2017, novas normas e procedimentos para a Regularização Fundiária (Reurb) rural e urbana foram disciplinados, visando promover às políticas públicas nesses territórios. Além de determinar parâmetros sobre a liquidação de créditos concedidos aos assentados da reforma agrária e a regularização fundiária no âmbito da Amazônia Legal; além de dispor sobre instrumentos visando a eficiência dos procedimentos de alienação de imóveis da União.

O presente artigo objetiva discutir brevemente os avanços e retrocessos do novo marco fundiário urbano e de sua regulamentação por meio do Decreto $\mathrm{n}^{\circ}$. 9.310, de 15 de março de 2018 e analisar o instrumento da legitimação fundiária introduzido no ordenamento fundiário brasileiro.

Nesse sentido, o art. $9^{\circ}$ da Lei $n^{\circ} .13 .465 / 2017$ (BRASIL, 2017) define a Reurb como o conjunto de procedimentos que abrangem medidas jurídicas, urbanísticas, ambientais e sociais destinadas à incorporação dos núcleos urbanos informais ao ordenamento territorial urbano e à titulação de seus ocupantes.

A legislação fundiária prescreve a necessidade de articular a Reurb à regularização urbanística e ambiental, o que viabiliza o ordenamento espacial, impedindo o adensamento do território. Portanto, visa legalizar a permanência de moradores de áreas urbanas ocupadas irregularmente para fins de moradia e, suplementarmente, proporcionar melhorias no meio ambiente urbano e na qualidade de vida da população (SOUZA; SILVA, 2019). Nessa linha, os órgãos públicos de patrimônio devem implementar políticas públicas de habitação, de acordo com os termos disciplinados na CRFB/88.

De acordo com Correia (2018), a regularização fundiária consiste no processo pelo qual se integra a moradia à cidade, por meio de direitos urbanísticos e infraestrutura urbana elementar, visando a efetivação da posse e do domínio de moradia adequada e digna, entendida como aquela capaz de proporcionar o pleno direito à cidade inclusiva e includente.

Verifica-se, aparentemente, que a opção adotada pelo legislador ordinário primou pela consecução do princípio da dignidade da pessoa humana (art. $1^{\circ}$, inciso III da CRFB/1988). Além de enfatizar um dos objetivos fundamentais da República, a erradicação da pobreza e da marginalização e redução das desigualdades sociais e regionais (art. $3^{\circ}$, inciso III da CRFB/1988). Em seu escopo, a lei evidencia o cumprimento da função social da propriedade em área pública ou privada (art. $5^{\circ}$, inciso XXIII da CRFB/1988), aliando-o ao direito social à moradia (art. $6^{\circ}$ da CRFB/1988); e, por fim, observando a política urbana prevista nos arts. 182 e 183 da CRFB/1988. 
O pressuposto da aplicação da legislação da regularização fundiária é que haja a consolidação de um núcleo urbano informal, compreendido como o assentamento que esteja com algum grau de irregularidade, conforme as seguintes hipóteses, de acordo com Cunha (2019, p. 17-18):

i) inexistência de aprovação do projeto de parcelamento no Município e por consequência, ausência de registro imobiliário;

ii) existência de aprovação municipal; no entanto, inexistência de registro imobiliário;

iii) existência de aprovação no Município, do registro imobiliário quanto ao parcelamento do solo, mas inexistência de averbação da construção;

iv) existência de aprovação municipal, do registro imobiliário; entretanto, a execução do projeto é diversa da que foi aprovada ou registrada, ou;

v) existência de aprovação municipal, do registro imobiliário, da averbação da construção; contudo ausência de titulação dos seus ocupantes atuais.

Cunha (2019) observa que é possível utilizar os instrumentos da regularização fundiária apenas para titular seus ocupantes, desde que as demais irregularidades forem sanadas, e, neste caso, há necessidade da elaboração do Projeto de Regularização Fundiária, nos termos do art. $21, \S 2^{\circ}$ do Decreto $n^{\circ}$. 9.310/2018. E conclui que, independentemente do rito adotado pelo poder público, algumas fases poderão ser suprimidas, desde que sejam precedidas por decisão fundamentada.

O poder público deverá formular políticas espaciais, dentro de suas competências, em conformidade aos princípios de sustentabilidade econômica, social e ambiental e ordenação territorial, buscando a ocupação do solo de maneira eficiente, combinando seu uso de forma funcional, nos termos do art. $9^{\circ}, \S 1^{\circ}$ da Lei $n^{\circ}$. 13.465/2017. Nesse sentido, o Superior Tribunal de Justiça (STJ), por meio da decisão monocrática advertiu:

RECURSO ESPECIAL No 1875962 - AM (2020/0122511-4) RELATOR : MINISTRO GURGEL DE FARIA RECORRENTE : MUNICÍPIO DE MANAUS PROCURADOR : LUCAS GRANGEIRO BONIFÁCIO - AM014198 RECORRIDO : MINISTÉRIO PÚBLICO DO ESTADO DO AMAZONAS DECISÃO Trata-se de recurso especial interposto pelo MUNICÍPIO DE MANAUS, com respaldo na alínea a do permissivo constitucional, contra acórdão do TRIBUNAL DE JUSTIÇA DO ESTADO DO AMAZONAS assim ementado (eSTJ fl. 187): EMENTA: APELAÇÃO CÍVEL. DIREITO URBANÍSTICO. AÇÃO CIVIL PÚBLICA. RESPONSABILIDADE DO ENTE MUNICIPAL. REGULARIZAÇÃO LOTEAMENTOS CLANDESTINOS. PRECEDENTE STJ. SENTENÇA MANTIDA. RECURSO DESPROVIDO. Merece ser desprovido o presente apelo, tendo em vista que a jurisprudência do Superior Tribunal de Justiça orienta no sentido de que o Município é titular do dever de regularizar loteamentos clandestinos ou irregulares, em conformidade com a legislação urbanística local (art. 40, § 5 , da Lei 6.766/1979), em especial à infraestrutura necessária para melhoria na malha urbana, como ruas, esgoto, energia e iluminação pública, de modo a atender aos moradores já instalados; - RECURSO CONHECIDO E DESPROVIDO. 
No caso examinado pelo STJ, o cerne da questão restringe-se exclusivamente quanto à responsabilização do Município, para fins de organização urbana, privilegiando-se a aplicação do princípio da legalidade ao diferenciar a figura do loteamento irregular disciplinado pela Lei $\mathrm{n}^{\circ}$ 6.766/1979 daquela prevista pelo art. $9^{\circ}$ da Lei $\mathrm{n}^{\circ}$. 13.465/2017, já que o núcleo urbano irregular previsto pela legislação de regularização fundiária é espontâneo.

$\mathrm{O} \S 2^{\circ}$ do art. $9^{\circ}$ da Lei prevê um limite temporal para a aplicação da Reurb promovida mediante legitimação fundiária, que será analisada no item 2, aos núcleos urbanos informais comprovadamente existentes até 22 de dezembro de 2016.

$\mathrm{O}$ art. $3^{\circ}, \S^{\circ}$ do Decreto $n^{\circ} .9 .310 / 2018$ faculta aos Municípios e ao Distrito Federal dispensarem as exigências relativas ao percentual e às dimensões de áreas destinadas ao uso público, ao tamanho dos lotes regularizados ou a outros parâmetros urbanísticos e edilícios. Desse modo, manteve-se a possibilidade da titulação, independentemente da urbanização (CORREIA, 2018).

A Lei $\mathrm{n}^{\mathrm{o}}$. 13.465/2017, em seu art. 11 prescreve conceitos fundamentais para a efetivação do procedimento de regularização fundiária urbana. Dentre eles, se destacam o de demarcação urbanística compreendido como procedimento dirigido a identificar os imóveis públicos e privados compreendidos pelo núcleo urbano informal e a obter a "anuência dos respectivos titulares de direitos inscritos na matrícula dos imóveis ocupados, culminando com averbação na matrícula destes imóveis da viabilidade da regularização fundiária, a ser promovida a critério do Município" (art. 11, IV da Lei no . 13.465/2017) (BRASIL, 2017).

Por fim, o instituto da Certidão de Regularização Fundiária entendido como documento expedido pelo Município ao término da Reurb, integrando-se o respectivo projeto de regularização fundiária aprovado, do termo de compromisso relativo a sua execução ${ }^{2}$ e, no caso da legitimação fundiária e da legitimação de posse, da listagem dos ocupantes do núcleo urbano informal regularizado, da devida qualificação destes e dos direitos reais que lhes foram conferidos (art. 11, V da Lei no. 13.465/2017) (BRASIL, 2017).

\section{MODALIDADES DA REURB}

O art. 13 da Lei $\mathrm{n}^{\mathrm{o}}$. 13.465/2017 prevê duas modalidades da Reurb, sendo elas:

i) A regularização fundiária de interesse social (Reurb-S) aplicável aos núcleos urbanos informais ocupados predominantemente por população de baixa renda, assim declarados em ato do poder público legitimado. No mesmo sentido, o art. $5^{\circ}, \S 1^{\circ}$ do Decreto $n^{\circ} .9 .310 / 2018$ garante a isenção de custas e emolumentos, entre outros, os atos registrais relacionados à Reurb-S, nos termos do Capítulo $\mathrm{V}$ da norma regulamentadora.

\footnotetext{
${ }^{2} \mathrm{O}$ art. $3^{\circ}, \S 2^{\circ}$ do Decreto $\mathrm{n}^{\circ}$. 9.310/2018 estabelece que: "O termo de compromisso referido no inciso $\mathrm{V}$ do caput conterá o cronograma da execução de obras e serviços e da implantação da infraestrutura essencial e poderá prever compensações urbanísticas e ambientais, quando necessárias”.
} 
Para fins da Reurb-S, considera-se como população de baixa renda, nos termos do art. $6^{\circ}$ do Decreto:

\begin{abstract}
Art. $6^{\circ}$ Para a classificação da Reurb na modalidade Reurb-S, a composição ou a faixa da renda familiar para definição de população de baixa renda poderá ser estabelecida em ato do Poder Público municipal ou distrital, consideradas as peculiaridades locais e regionais de cada ente federativo.

Parágrafo único. A renda familiar prevista no caput não poderá ser superior ao quíntuplo do salário mínimo vigente no País. (BRASIL, 2018).
\end{abstract}

Apesar do Decreto estabelecer um limite máximo de salários mínimos vigentes para definir a categoria população de baixa renda, em seu parágrafo único, o caput permite a discricionariedade do ente municipal ou distrital apreciar elementos socioeconômicos locais e regionais para definição de um quantitativo. Inclusive, para a adoção de uso múltiplo do imóvel, desde que este integre a renda dos ocupantes e não ultrapasse o valor estabelecido pela lei.

Outro ponto importante é o previsto no art. 95 da Lei $n^{\circ} .13 .465 / 2017$, ao estabelecer que:

Art. 95. O Decreto-Lei $\mathrm{n}^{\mathrm{o}} 1.876$, de 15 de julho de 1981, passa a vigorar com as seguintes alterações:

"Art. $1^{\circ}(\ldots)$

$\S 2^{\circ}$ Considera-se carente ou de baixa renda, para fins da isenção disposta neste artigo, o responsável por imóvel da União que esteja devidamente inscrito no Cadastro Único para Programas Sociais do Governo Federal (CadÚnico), ou aquele responsável, cumulativamente:

I - cuja renda familiar mensal seja igual ou inferior ao valor correspondente a cinco salários mínimos; e

II - que não detenha posse ou propriedade de bens ou direitos em montante superior ao limite estabelecido pela Receita Federal do Brasil, para obrigatoriedade de apresentação da Declaração de Ajuste Anual do Imposto de Renda Pessoa Física.

(...)

$\S 5^{\circ}$ A exigência de que trata o inciso II do $\S 2^{\circ}$ deste artigo, não se aplica aos beneficiários da Reurb-S.” (NR) (grifos nossos) (BRASIL, 2017)

Esse Decreto-Lei citado no art. 95 dispensa do pagamento de foros e laudêmios os titulares do domínio útil dos bens imóveis da União, nos casos que especifica, e dá outras providências.

Para efeitos de inscrição de pessoas de baixa renda no Cadastro Único para Programas Sociais do Governo Federal citado no $\S 2^{\circ}$, o Decreto $n^{\circ}$. 6.135/2007, define-se como famílias de baixa renda aquelas com até meio salário mínimo de renda per capita, ou renda familiar de até 03 (três) salários mínimos.

ii) A regularização fundiária de interesse especial (Reurb-E), hipótese aplicável aos núcleos urbanos informais ocupados por população não qualificada como baixa renda. Em outros termos, os núcleos urbanos informais constituídos por unidades imobiliárias não residenciais poderá ser feita por meio de Reurb-E (art. $5^{\circ}, \S 6^{\circ}$ do Decreto no $.9 .310 / 2018$ ). 
Conforme a redação dada pelo Decreto $n^{\circ}$. 9.597/2018, a classificação da modalidade da Reurb poderá ser feita a critério do município ou do distrito federal, de modo a promover a integração social e a geração de emprego e renda no núcleo urbano informal regularizado (art. $5^{\circ}, \S 7^{\circ}$ do Decreto $\left.n^{\circ} .9 .310 / 2018\right)$. Cunha considera que de acordo com a nova redação dada pelo Decreto $\mathrm{n}^{\mathrm{o}}$. 9.597/2018 é possível classificar o mesmo “(...) núcleo urbano informal em mais de uma modalidade de REUB considerando o caso concreto (e não pela predominância) permite ao Município o ressarcimento pelo custo de PRF [Projeto de Regularização Fundiária] e pela execução de obras de infraestrutura essencial" (CUNHA, 2019, p. 19).

A discussão que merece destaque versa sobre a natureza da Reurb inominada. Cunha (2019) advoga pela tese de que a Reurb inominada se trata de um rito acelerado destinado a processar a regularização fundiária, que poderá ser empregado na Reurb-S e na Reurb-E, uma vez que sua previsão legal está disciplinada nas "Disposições Finais e Transitórias", tanto da Lei ${ }^{\circ}$. 13.465/2017 (art. 69), quanto no Decreto $n^{\circ}$. 9.310/2018 (art. 87).

A legislação prevê quatro ritos para processar a regularização fundiária, sendo eles:

i) Reurb ( $\mathrm{S}$ ou E) precedida de demarcação urbanística, nos termos do art. 19 da Lei $\mathrm{n}^{\text {o }}$. 13.465/2017 e do art. 12 do Decreto $n^{\circ}$. 9.310/2018.

ii) Reurb ( $\mathrm{S}$ ou $\mathrm{E}$ ) com rito administrativo, conforme disposição do art. 32 Lei $\mathrm{n}^{\mathbf{0}}$. 13.465/2017 e do art. 21 do Decreto $n^{\circ}$. 9.310/2018.

iii) Reurb (S ou E) pelo rito da regularização inominada, prevista no art. 69 da Lei $n^{\circ}$. 13.465/2017 e do art. 87 do Decreto $n^{\circ}$. 9.310/2018.

iv) Abertura de matrícula para a gleba ou área pública (art. 195-A e art. 195-B da Lei no . 6.015/1973);

v) Especialização de fração ideal (art. 45 da Lei n ${ }^{\circ}$. 13.465/2017 e do art. 43 do Decreto $n^{\text {o. }}$ 9.310/2018).

Conforme disposição contida no art. 21 do Decreto $n^{\circ} .9 .310 / 2018$, a Reurb poderá ser realizada em fases, possibilitando ao ente legitimado a dividir o assentamento informal em núcleos menores, precedida ou não da demarcação urbanística, incluindo ou não as áreas que necessitem de estudos técnicos ambientais. A doutrina ventila a possibilidade excepcional de se realizar a Reurb de unidade isolada, nas hipóteses quando há lotes em áreas de risco ou em áreas ambientalmente protegidas, precedida de estudos técnicos.

\section{LEGITIMAÇÃO FUNDIÁRIA: UM NOVO INSTITUTO E MUITAS POLÊMICAS}

Dentre os institutos jurídicos previstos no art. 15 da Lei n ${ }^{\circ}$. 13.465/2017, que poderão ser empregados pelos Municípios e o Distrito Federal para a promoção da Reurb, encontra-se 
a legitimação fundiária. Esse dispositivo trata-se de uma norma exemplificativa, que possui como escopo dar segurança jurídica aos beneficiários que possuem imóveis públicos ou privados em núcleos urbanos informais e objetivam regularizá-los e empregar medidas de urbanização, social e ambientais nesses espaços. No mesmo sentido, o art. 15 da Lei $\mathrm{n}^{\circ}$. $13.465 / 2017$ e o art. $8^{\circ}$ do Decreto $n^{\circ}$. 9.310/2018 apresentam a natureza de numerus apertus.

O Capítulo II, Seção III da Lei ${ }^{\circ}$. 13.465/2017, em seus artigos 23 e 24 cuidou o instituto da legitimação fundiária, considerado uma forma originária de aquisição do direito real de propriedade conferido por ato do poder público, exclusivamente no âmbito da Reurb, àquele que detiver em área pública ou possuir em área privada, como sua, unidade imobiliária com destinação urbana, integrante de núcleo urbano informal consolidado existente em 22 de dezembro de 2016, não sendo aplicável a situações futuras.

O Decreto regulamentador reforçou o limite temporal de 22 de dezembro de 2016 (data da edição da Medida Provisória 759/2016, que foi convertida na Lei da Reurb) para a utilização desse instrumento de regularização fundiária.

Desse modo, nos termos do art. 10, da Lei no. 13.465/2017 é fundamental a identificação dos núcleos urbanos informais pelos entes federados que devam ser regularizados, organizá-los e assegurar a prestação de serviços públicos aos seus ocupantes.

$O$ art. $23, \S 1^{\circ}$ da Lei estabelece as condições aos beneficiários, restringindo as hipóteses de aplicação aos casos de núcleos passíveis de Reurb-S, sendo elas:

\footnotetext{
Art. 23. (...)

$\S 1^{\circ}$. Apenas na Reurb-S, a legitimação fundiária será concedida ao beneficiário, desde que atendidas as seguintes condições:

I - o beneficiário não seja concessionário, foreiro ou proprietário de imóvel urbano ou rural;

II - o beneficiário não tenha sido contemplado com legitimação de posse ou fundiária de imóvel urbano com a mesma finalidade, ainda que situado em núcleo urbano distinto; e

III - em caso de imóvel urbano com finalidade não residencial, seja reconhecido pelo poder público o interesse público de sua ocupação.
}

Contudo, o legislador não estabeleceu qualquer requisito quando se trata de Reurb-E, o que afetaria o direito à moradia digna.

Em qualquer das modalidades da Reurb, o ocupante poderá adquirir a unidade imobiliária com destinação urbana livre e desembaraçada de quaisquer ônus, direitos reais, gravames ou inscrições, eventualmente existentes em sua matrícula de origem, exceto quando disserem respeito ao próprio legitimado, conforme disposto no art. $23, \S 2^{\circ}$ da Lei.

A Lei inova com a possibilidade de aquisição do direito de propriedade, nos casos de Reurb-S, de imóveis públicos pertencentes à União, aos Estados, ao Distrito Federal e aos 
Municípios, e às suas entidades vinculadas. $\mathrm{O}$ poder público poderá atribuir o domínio ao ocupante que não constava na listagem inicial para a concessão da legitimação fundiária, mediante cadastramento complementar, sem prejuízo dos direitos de quem haja constado na listagem inicial.

O poder público encaminhará a CRF para registro imediato da aquisição de propriedade, dispensados a apresentação de título individualizado e as cópias da documentação referente à qualificação do beneficiário, o projeto de regularização fundiária aprovado, a listagem dos ocupantes e sua devida qualificação e a identificação das áreas que ocupam.

$\mathrm{O}$ art. 24 estabelece a discricionariedade ao Município de aplicar os instrumentos previsto na Lei da Reurb e titular com o direito de propriedade os ocupantes que iniciaram os procedimentos de regularização fundiária urbana previstos pela Lei ${ }^{\circ} 11.952$, de 25 de junho de 2009, e não concluídos.

Reis e Lelis (2018) afirmam que a escolha desse instrumento jurídico de regularização fundiária teria natureza de ato administrativo discricionário, apesar de não haver qualquer indicação legal nesse sentido. A partir desse raciocínio, os legitimados somente teriam o direito subjetivo de requerer o processamento da Reurb. Caberia ao Município e ao Distrito Federal a conveniência e oportunidade na eleição do instrumento mais adequado a ser implementado na regularização.

De acordo com os autores, nos casos de aplicação de legitimação fundiária em área privada, a natureza seria de expropriação. Alegam que se estaria diante de um confisco de bem, vedado pelo art. 5, XXIV, da CRFB/88 (REIS; LELIS, 2018). No mesmo sentido, aponta Rosenvald (s.d.):

(...) De fato, a legitimação fundiária de bens particulares mais se assemelha a uma desapropriação extrajudicial, na qual, ausentes balizas, o titular de um terreno invadido em 2016 será expropriado sem direito a indenização, caso a municipalidade considere que a ocupação estava consolidada Cria-se uma fuga da usucapião pela via oblíqua, eximindo-se dos requisitos do lapso temporal e do "animus domini".

No entanto, em se tratando de área pública, a transferência do bem ao particular por meio da legitimação fundiária se assemelharia aos contratos de compra e venda e doação, especialmente por força do art. 71, que dispensa a desafetação e as exigências previstas no inciso I do caput do art. 17 da Lei ${ }^{\circ}$ 8.666/1993.

Reis e Lelis (2018) defendem ainda que se considerarmos a natureza do ato como vinculada se estaria diante de uma hipótese de usucapião de bem público, vedada pela Constituição Federal, em seu art. 183. Rosenvald (s.d.) ao tratar da matéria afirma que: 
perderão a sua titularidade originária, o que presume um aparente "confisco" - que não coincide com as justificadas hipóteses constitucionais de desapropriação-sanção pelo cultivo de psicotrópicos ou recurso ao trabalho escravo.

Por esses e outros pontos levantados pela doutrina e pela jurisprudência dos tribunais superiores foi proposta pela Procuradoria Geral da República (PGR) a ADI 5.771/DF, em face da Lei ${ }^{\circ} 13.465 / 2017$, como se passa a analisar.

\section{A LEGITIMAÇÃo FUNDIÁRIA E O QUESTIONAMENTO DA SUA CONSTITUCIONALIDADE PELA AÇÃO DIRETA DE INCONSTITUCIONALIDADE 5.771/DF}

A ADI 5.771DF, com pedido de medida cautelar, foi proposta pela PGR, objetivando a declaração de inconstitucionalidade integral do disposto na Lei Geral de Regularização Fundiária. Dentre os argumentos elencados mais relevantes pela PGR estão:

1. Os vícios relacionados à ausência dos requisitos de relevância e urgência, bem como à regulamentação de matéria vedada pela Constituição, na via da medida provisória, não são afastados pela sua conversão em lei.

2. Medida provisória que se propõe a reestruturar a legislação sobre regularização fundiária urbana e rural não atende ao requisito de urgência, previsto no art. 62, caput da Constituição. (BRASIL, 2017).

De acordo com a fundamentação da PGR, a lei federal buscou resolver problemas estruturais existentes sobre questões agrárias, relativas à grilagem de terra e ao desmatamento. $\mathrm{Na}$ parte urbana, a finalidade legislativa era solucionar problemas de decênios sobre o crescimento desordenado das cidades, por meio da titulação dos beneficiários. Todavia, tais impactos já experimentados a muito tempo na realidade brasileira, não são objetos para serem tratados por meio de uma medida provisória, que estende o vício formal na conversão em lei, com a usurpação da função legislativa do Congresso Nacional.

Acrescido o argumento de que certos instrumentos dependiam de regulamentação por normas infralegais, carecendo de periculum in mora necessário para justificar a edição da medida. Prossegue a Procuradoria alegando que:

(...)

5. A Lei 13.465/2017 extrapolou a competência da União para legislar sobre normas gerais de direito urbanístico (Constituição, art. 24, I) e avançou sobre a competência dos Municípios (Constituição, arts. 30, I e VIII e 182, §2º), ignorando a posição de protagonismo desses entes acerca das matérias urbanísticas. (BRASIL, 2017).

A regularização fundiária urbana prevista na lei federal exorbitou a competência da União para dispor sobre normas gerais, usurpando a competência legislativa dos Municípios de 
ordenar seu território a luz de sua realidade. Nesse sentido, o Supremo Tribunal Federal (STF) já decidiu: “(...) os Municípios com mais de vinte mil habitantes e o Distrito Federal podem legislar sobre programas e projetos específicos de ordenamento do espaço urbano por meio de leis que sejam compatíveis com as diretrizes fixadas no plano diretor" (BRASIL, 2016).

Assim, a competência do ente municipal não se exaure na elaboração do plano diretor, podendo editar atos legislativos para tratar sobre política urbana em consonância com o primeiro.

Nessa esteira, o art. 11, I da lei federal ao definir o núcleo urbano, para efeitos da Reurb e da aplicação de seus institutos, considera a extensão da área, independentemente da propriedade do solo, ainda que situado em área qualificada ou inscrita como rural, independentemente de previsão a respeito no plano diretor. O STF já emitiu decisão no sentido de que qualquer legislação que disponha em sentido contrário ao plano diretor dependerá de uma prévia e específica alteração esse instrumento.

Ainda se chama a atenção na ADI 5.771/DF para o argumento de que:

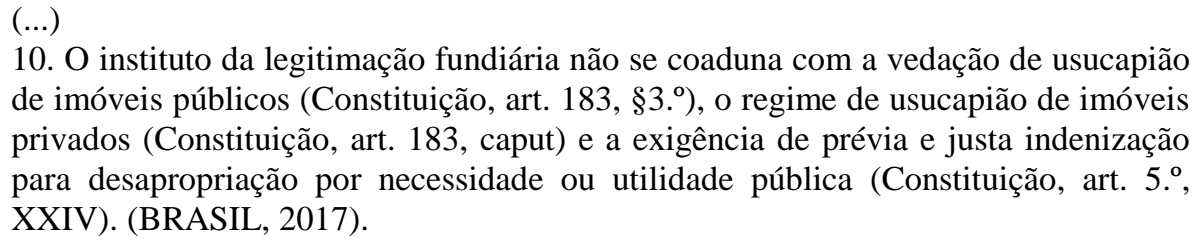
de imóveis públicos (Constituição, art. 183, §3..), o regime de usucapião de imóveis privados (Constituição, art. 183, caput) e a exigência de prévia e justa indenização para desapropriação por necessidade ou utilidade pública (Constituição, art. 5. ${ }^{\circ}$, XXIV). (BRASIL, 2017).

Em relação à legitimação fundiária, a ADI 5.771/DF invoca o argumento de que há critérios a serem verificados em relação a ocupação do imóvel objeto de regularização nas situações concretas.

Os critérios legais estabelecidos têm natureza de conceitos jurídicos indeterminados, tais como, "de difícil reversão, considerados o tempo da ocupação", "natureza das edificações", "localização das vias de circulação e a presença de equipamentos públicos", "outras circunstâncias a serem avaliadas pelo Município", "destinação urbana".

De acordo com Cunha (2018, p. 146), o que a lei pretende é "inibir a formação de novos núcleos informais, tenha como beneficiário alguém já titulado em outra regularização". Em seus argumentos a PGR reforça que:

Não se verifica justificativa razoável para que o instituto da legitimação fundiária esteja isento de critérios definidos, ao tempo, ao modo e à área da ocupação. (...) A destinação de terras públicas a particulares pauta-se pelo interesse público, que deve se orientar pelos princípios da função social da propriedade urbana e das funções sociais da cidade. O instituto é incompatível com o sistema constitucional de proteção da propriedade. (BRASIL, 2017) 
A legitimação fundiária constitui uma intervenção do Estado na propriedade privada e na destinação de terras públicas. Portanto, deve observar os preceitos constitucionais mínimos sobre a ocupação e a ausência de previsão de indenização sobre áreas privadas.

Ainda é sustentado a ofensa do princípio da isonomia na instituição de requisitos mais rigorosos para população de baixa renda usufruir de política pública de regularização fundiária urbana, em relação aqueles fixados na Reurb-E.

\section{CONCLUSÕES}

A regularização fundiária urbana, como instrumento de política urbana, deve ir além da formalização da propriedade, garantindo o direito à cidade e à moradia digna, que abrange habitação, trabalho, lazer, mobilidade, educação, saúde e desenvolvimento sustentável.

Conforme analisado, a possibilidade de violação material do novo marco legal face a Constituição federal, dentre outros pontos, versa sobre a distribuição de títulos dominiais, decorrentes da privatização de terras, sejam públicas ou privadas, desprovida de regras claras sobre os limites do direito de habitação e dos procedimentos de regularização fundiária urbana. Apesar da finalidade legislativa seja, em um primeiro momento, a formalização de titulação, essa deve se atrelar a garantia da integração dos ocupantes dos imóveis à vida urbana.

Embora a legitimação fundiária seja um instrumento de vanguarda, pois confere ao beneficiário um modo de aquisição originária do direito real de propriedade pública ou privada ocupada em área objeto de regularização fundiária, pesa sobre esse instituto a alegação de inconstitucionalidade, uma vez que excepcional a regra constitucional da vedação de usucapião de imóveis públicos (art. 183, §3. ${ }^{\circ}$, da $\mathrm{CRFB} / 88$ ), o regime de usucapião de imóveis privados (art. 183, caput, da CRFB/88) e a exigência de prévia e justa indenização para desapropriação por necessidade ou utilidade pública (art. 5. ${ }^{\circ}$ XXIV, da CRFB/88).

\section{REFERÊNCIAS}

BRASIL. Lei no $\mathbf{1 3 . 4 6 5}$, de 11 de julho de 2017. Dispõe sobre a regularização fundiária rural e urbana, sobre a liquidação de créditos concedidos aos assentados da reforma agrária e sobre a regularização fundiária no âmbito da Amazônia Legal; institui mecanismos para aprimorar a eficiência dos procedimentos de alienação de imóveis da União; altera as Leis $\mathrm{n}^{\text {os }} 8.629$, de 25 de fevereiro de 1993 , 13.001, de 20 de junho de 2014 , 11.952, de 25 de junho de 2009, 13.340, de 28 de setembro de 2016, 8.666, de 21 de junho de 1993, 6.015, de 31 de dezembro de 1973, 12.512, de 14 de outubro de 2011 , 10.406, de 10 de janeiro de 2002 (Código Civil), 13.105, de 16 de março de 2015 (Código de Processo Civil), 11.977, de 7 de julho de 2009, 9.514, de 20 de novembro de 1997, 11.124, de 16 de junho de 2005, 6.766, de 19 de dezembro de 1979, 10.257, de 10 de julho de 2001, 12.651, de 25 de maio de 2012, 13.240, de 30 de dezembro de 2015, 9.636, de 15 de maio de 1998, 8.036, de 11 de maio de 1990, 13.139, de 26 
de junho de 2015, 11.483, de 31 de maio de 2007, e a 12.712, de 30 de agosto de 2012, a Medida Provisória $\mathrm{n}^{\mathrm{o}} 2.220$, de 4 de setembro de 2001, e os Decretos-Leis n ${ }_{-}^{\circ} 2.398$, de 21 de dezembro de 1987, 1.876, de 15 de julho de 1981, 9.760, de 5 de setembro de 1946, e 3.365, de 21 de junho de 1941; revoga dispositivos da Lei Complementar ${ }^{\circ} 76$, de 6 de julho de 1993, e da Lei $\mathrm{n}^{\circ}$ 13.347, de 10 de outubro de 2016; e dá outras providências.

Diário Oficial [da] República Federativa do Brasil, Brasília, DF, 08 set. 2017. Disponível em: <http://www.planalto.gov.br/ccivil_03/_Ato2015-2018/2017/Lei/L13465.htm>. Acesso em: 30 jun. 2020.

BRASIL. Decreto $\mathbf{n}^{\mathbf{0}}$. 9.310, de 15 de março de 2018. Institui as normas gerais e os procedimentos aplicáveis à Regularização Fundiária Urbana e estabelece os procedimentos para a avaliação e a alienação dos imóveis da União. Disponível em: $<$ http://www.planalto.gov.br/ccivil_03/_Ato2015-2018/2018/Decreto/D9310.htm>. Acesso em: 01 jul. 2020.

BRASIL. Lei $\mathbf{n}^{0}$ 6.015, de 31 de dezembro de 1973. Dispõe sobre os registros públicos e dá outras providências. Disponível em: <https://www2.camara.leg.br/legin/fed/lei/1970-1979/lei6015-31-dezembro-1973-357511-normaatualizada-pl.pdf >. Acesso em: 05 jul. 2020.

BRASIL. Superior Tribunal de Justiça. Recurso Especial 1875962/AM. Apelação Cível. Direito Urbanístico. Ação Civil Pública. Responsabilidade do ente municipal. Regularização loteamentos clandestinos. Precedente STJ. Sentença Mantida. Recurso Desprovido. Recorrente: Município de Manaus. Recorrido: Ministério Público do Estado do Amazonas. Relator: Min. Gurgel de Faria, 01 de julho de 2020. Disponível em: <https://ww2.stj.jus.br/processo/dj/documento/mediado/?tipo_documento=documento\&comp onente $=$ MON\&sequencial $=111040622 \&$ num registro $=202001225114 \&$ data $=20200701$ > Acesso em: 03 jul. 2020.

BRASIL. Supremo Tribunal Federal. Recurso Extraordinário 609.740/DF. Constitucional. Ordem Urbanística. Competências Legislativas. Poder normativo municipal. Art. 30, VIII e art. 182, caput, da Constituição Federal. Plano Diretor. Diretrizes básicas de ordenamento territorial. Compreensão. Disponível em: http://redir.stf.jus.br/paginadorpub/paginador.jsp?docTP=TP\&docID=10351534>. Acesso em: 05 out. 2020.

BRASIL. Supremo Tribunal Federal. ADI 5.771/DF. Ação Direta de Inconstitucionalidade, com pedido de medida cautelar, face ao disposto na Lei Federal $\mathrm{n}^{\circ} 13.465$, de 11 de julho de 2017, que "dispõe sobre a regularização fundiária rural e urbana, sobre a liquidação de créditos concedidos aos assentados da reforma agrária e sobre a regularização fundiária no âmbito da Amazônia Legal; institui mecanismos para aprimorar a eficiência dos procedimentos de alienação de imóveis da União" e altera numerosas outras leis. Disponível em: < http://portal.stf.jus.br/processos/detalhe.asp?incidente=5255150>. Acesso em: 07 out. 2020. 
CARMONA, P. A. C.; MENDES, L. J. M.. Função social da cidade: norma princípio, cláusula geral ou conceito jurídico indeterminado? Revista Magister de Direito Ambiental e Urbanístico, n. 65, p. 28, abr./maio 2016.

CORREIA, A. F. Direito da regularização fundiária urbana e autonomia municipal: a conversão da Medida Provisória n. ${ }^{\circ}$ 759/2016 na Lei Federal n. ${ }^{\circ}$ 13.465/2017 e as titulações da Prefeitura da cidade do Rio de Janeiro no primeiro quadrimestre de 2017. In: PENALVA, A.; CORREIA, A.F.; MARAFON, G.J.; SANT'ANNA, M.J.G. (eds.). Rio de Janeiro: uma abordagem dialógica sobre o território fluminense [online]. Rio de Janeiro: EdUERJ, 2018, p. 192-232. Disponível em: < http://books.scielo.org/id/tkysm/pdf/penalva-9788575115169-09.pdf>. Acesso em: 30 jun. 2020.

CUNHA, M. F. F. Manual de regularização fundiária urbana - Reurb. 1. ed., 5. tir., Salvador: JusPodivm, 2019.

REIS, E. M.; LELIS, N. Legitimação fundiária - Natureza jurídica e aplicabilidade prática. Revista Magister de Direito Ambiental e Urbanístico, Porto Alegre, v. 13, n. 75, dez. 2017/jan. 2018, p. 47-63, 2018.

SOUZA, J. R.; SILVA, R. M. A. Regularização fundiária urbana após a lei n⿳0. 13465/2017. 2019. 21 f. Artigo Científico (Especialização em Direito Imobiliário), Centro Universitário UNIFAMETRO, Ceará, 2019. Disponível em: http://repositorio.unifametro.edu.br/jspui/bitstream/123456789/52/1/JOS\%c3\%89\%20REUD SON\%20DE\%20SOUZA\%20\%20ROZANA\%20MARIA\%20ARA\%c3\%9aJO\%20DA\%20SILVA.pdf >. Acesso em: 01 jul. 2020. 